\title{
Evaluation of oxidant, antioxidant, and SIOOB levels in patients with conversion disorder
}

\author{
This article was published in the following Dove Press journal: \\ Neuropsychiatric Disease and Treatment \\ 13 July 2016 \\ Number of times this article has been viewed
}

\author{
Hasan Büyükaslan' \\ Sultan Basmacı Kandemir ${ }^{2}$ \\ Mehmet Asoğlu ${ }^{3}$ \\ Halil Kaya ${ }^{4}$ \\ Mehmet Tahir Gökdemir ${ }^{\prime}$ \\ İbrahim Fatih Karababa ${ }^{3}$ \\ Fatih Güngörmez ${ }^{5}$ \\ Fethiye Kılıçaslan ${ }^{6}$ \\ Emin Șavik ${ }^{7}$ \\ 'Department of Emergency Medicine, \\ Faculty of Medicine, Harran \\ University, ${ }^{2}$ Department of Psychiatry, \\ Balıklıgöl State Hospital, ${ }^{3}$ Department \\ of Psychiatry, Faculty of Medicine, \\ Harran University, Sanliurfa, ${ }^{4}$ Bursa \\ Yüksek Ihtisas Training and Research \\ Hospital, Bursa, ${ }^{5}$ Department of \\ Emergency Medicine, Mehmet Akif \\ Inan Research Hospital, ${ }^{6}$ Department \\ of Child and Adolescent Psychiatry, \\ ${ }^{7}$ Department of Biochemistry, Faculty \\ of Medicine, Harran University, \\ Sanliurfa, Turkey
}

Introduction: Various psychodynamic, neurobiological, genetic, and sociocultural factors are believed to be involved in the etiology of conversion disorder (CD). Oxidative metabolism has been shown to deteriorate in association with many health problems and psychiatric disorders. We evaluated oxidative metabolism and S100B levels in the context of this multifactorial disease.

Methods: Thirty-seven patients with CD ( 25 females and 12 males) and 42 healthy volunteers (21 females and 21 males), all matched for age and sex, were included in this study. The total oxidant status, total antioxidant status, oxidative stress index, and S100B levels were compared between the two groups.

Results: The total oxidant status, oxidative stress index, and S100B levels were significantly higher in patients with $\mathrm{CD}$ than in the control group, whereas the total antioxidant status was significantly lower.

Conclusion: $\mathrm{CD}$ is associated with deterioration of oxidative metabolism and increased neuronal damage.

Keywords: conversion disorder, oxidative stress, S100B

\section{Introduction}

Conversion disorder (CD) was first described by Freud and Breuer ${ }^{1}$ as the transfer of different emotional problems and conflicts to the sensory and movement systems, resulting in their manifestation as physical symptoms. Most symptoms of CD affect functionality and mimic sensorimotor neurological disorders. Motor and sensory losses can be seen in affected patients and include dizziness, balance disorders, fainting, loss of consciousness, nonepileptic seizures, dysphagia, aphonia, anosmia, loss of vision, double vision, paresthesia, anesthesia, visible symptoms, and paralysis. ${ }^{2,3} \mathrm{CD}$ is most frequently seen in patients aged between 15 years and 35 years. ${ }^{4}$ The etiology is not fully understood; however, it is thought that sex, psychological stress, intrafamilial conflict, childhood trauma, low socioeconomic status, and problems encountered in the social environment play a role in the emergence of the disease.

There is a balance between oxidative and antioxidative systems within organisms. When these systems are unbalanced in favor of oxidants, oxidative stress results. ${ }^{5}$ It has been shown that disorders involving the release of free radicals or failure of the antioxidant defense system may play a role in the pathophysiology of neuropsychiatric disorders. ${ }^{6}$ To date, impaired oxidative stability has been associated with depression, anxiety, attention-deficit hyperactivity disorder (ADHD), obsessive-compulsive disorder (OCD), and nocturnal enuresis. ${ }^{7-11} \mathrm{~S} 100 \mathrm{~B}$ protein is secreted by the glial cells of the brain and acts to modulate the proliferation and alteration of neurons. ${ }^{12} \mathrm{~S} 100 \mathrm{~B}$ has
Correspondence: Hasan Büyükaslan Department of Emergency Medicine, Faculty of Medicine, Harran University, Meteorology Street, 63300 Sanliurfa, Turkey

Tel +904143183402

Fax +90414315 II8I

Email hasanbuyukaslan@hotmail.com (c) (1) (5) 2016 Büyükaslan et al. This work is published and licensed by Dove Medical Press Limited. The full terms of this license are available at https://www.dovepress.com/terms.php cc. ${ }_{\mathrm{BY}} \mathrm{NC}$ and incorporate the Creative Commons Attribution - Non Commercial (unported, v3.0) License (http://creativecommons.org/licenses/by-nc/3.0/). By accessing the work you hereby accept the Terms. Non-commercial uses of the work are permitted without any further permission from Dove Medical Press Limited, provided the work is properly attributed. For permission for commercial use of this work, please see paragraphs 4.2 and 5 of our Terms (https://www.dovepress.com/terms.php). 
neurotrophic and neuroprotective effects at physiological nanomolar concentrations, but the higher concentrations that occur following astrocytic death have been shown to be neurotoxic. Recently, it has been shown that S100B levels change in many psychiatric disorders. Specifically, there is a relationship between $\mathrm{S} 100 \mathrm{~B}$ protein levels and neurodegenerative diseases, such as Alzheimer's disease, mood disorders (major depression and bipolar disorder), and schizophrenia. ${ }^{13}$ It has also been shown that the blood levels of S100B protein increase after damage to the cells of the brain. Some studies on schizophrenia have demonstrated increased S100B protein levels during the acute phase of the disease. ${ }^{14,15}$ These data raise the question of whether there is a relationship among CD, oxidative metabolism, and S100B protein levels because this condition is more often seen in people exposed to intensely inadequate psychosocial conditions that increase stress and cause a variety of emotional problems. When we searched the literature, we were unable to find any reports concerning a potential relationship between oxidative metabolism and S100B protein levels.

However, the etiology of CD is not fully known; symptoms such as motor and sensory deficits, nonepileptic seizures, and exposure to increased stress directed us to investigate the potential relationship between oxidative stress and CD. In this study, we evaluated the oxidative-antioxidative status and S100B protein levels in people with CD.

\section{Methods}

Thirty-seven patients (12 males and 25 females; age range, 18-60 years) admitted to the emergency department with a diagnosis of CD in accordance with the Turkish version of the Diagnostic and Statistical Manual of Mental Disorders, 4th edition criteria between May and August 2015 were included in this study. All physical examination findings were normal, and there were no evident organic pathologies or history of drug use. Patients were diagnosed with CD by a psychiatrist using a structured psychiatric interview based on the Diagnostic and Statistical Manual of Mental Disorders, 4th edition. Forty-two healthy volunteers (21 females and 21 males), matched for age and sex of the experimental group, were included in this study. Exclusion criteria included mental retardation, alcohol use, tobacco use, depression, anxiety, and ecstasy use. Patients with epilepsy, migraine, multiple sclerosis, Parkinson's disease, schizophrenia and other psychotic disorders, and dementia and other cognitive disorders were also excluded from the study. The control group comprised physically and psychologically healthy volunteers. Drug, alcohol, tobacco, and psychoactive substance users were excluded from the control group. Approval for the study was granted by the Harran University Institutional Ethics Committee, and written informed consent was obtained from all participants.

\section{Blood sampling}

Each patient's complete blood count was evaluated using an automatic blood counting device (Abbott Cell Dyn 3500; Abbott Laboratories, Abbott Park, IL, USA). Blood samples taken for biochemical analyses were centrifuged at 3,500 rpm for 5 minutes, and the cellular components were discarded. Serum samples were stored at $-80^{\circ} \mathrm{C}$ until analysis. The serum total antioxidant status (TAS) and total oxidant status (TOS) were measured using a colorimetric autoanalyzer (Abbott Aeroset; Abbott Laboratories), and these levels were used to calculate the oxidative stress index (OSI). Plasma S100B levels were measured using an ELISA kit (BioVendor Laboratorni Medicina, Brno, Czech Republic).

\section{Measurement of TAS}

Serum TAS was measured using an automated method previously defined by Erel. ${ }^{16}$ In the Fenton reaction, a ferrous ion solution (Reagent 1 ) is mixed with a hydrogen peroxide solution (Reagent 2), resulting in the release of potent hydroxyl radicals. Brown-colored dianisidinyl radical cations, which are also potent radicals, are subsequently produced by the hydroxyl radicals. This assay determines the antioxidative capacity of the sample against the potent free radical reactions triggered by the hydroxyl radical. The assay has excellent precision values with a coefficient of variation of $<3 \%$. Results are expressed as millimoles of Trolox equivalent per liter.

\section{Measurement of TOS}

Measurement of the serum TOS level was performed using a new automated method described by Erel. ${ }^{17}$ The ferrous ion-O-dianisidine complex is oxidized by the oxidants present in the sample, yielding ferric ions. Glycerol was used to enhance the oxidation reaction. In an acidic medium, ferric ions form a colorful complex with xylenol orange. The intensity of the color, which can be measured spectrophotometrically, is related to the total quantity of oxidant molecules present in the sample. The assay is calibrated using hydrogen peroxide. Data are expressed as micromoles of hydrogen peroxide equivalent per liter.

\section{OSI}

The OSI is defined as the ratio of the TOS to TAS and is expressed as a percentage. Following normalization of the 
TOS and TAS units, the OSI value was calculated based on the following formula: OSI (arbitrary units) $=$ TOS $(\mu \mathrm{mol}$ $\mathrm{H}_{2} \mathrm{O}_{2}$ equiv/L)/TAS (mmol Trolox equiv/L) $\times 10^{-1} .{ }^{17}$

\section{Measurement of serum SIOOB}

Commercially available ELISA kits (BioVendor Laboratorni Medicina) were used to measure serum S100B levels. Briefly, the samples were incubated with a biotin-labeled monoclonal antihuman S100B antibody for 120 minutes and then washed. The samples were then transferred to ELISA plate wells and incubated for 60 minutes with captured S100B antibody. The plate was then washed, and streptavidin-horse radish peroxidase enzyme conjugate was added to the wells. After a 30-minute incubation, a final wash was performed. Conjugated horse radish peroxidase enzyme remaining in the plate was then allowed to react with the substrate solution (TMB). Finally, the reaction was stopped by addition of an acidic solution. The absorbance of the resulting yellow product was measured.

\section{Statistical analysis}

The results are presented as mean $\pm \mathrm{SD}$ or as a percentage. Categorical variables were compared using the chi-square test. For continuous variables, differences between the two groups were assessed using an unpaired $t$-test. A $P$-value of $<0.05$ was considered as statistically significant. Analyses were performed using SPSS 11.5 statistical software (SPSS Inc., Chicago, IL, USA).

\section{Results}

Twenty-five $(68 \%)$ of the 37 patients were females, with a mean age of $32.49 \pm 12.59$ years (age range, 18-60 years). Twenty-one $(50 \%)$ of the 42 healthy volunteers enrolled in the study were females, with a mean age of $28.88 \pm 8.79$ years (age range, 19-62 years). There were no statistically significant differences in age, sex, education level, or occupation between the patient and control groups $(P>0.05$ for all) (Table 1). The TOS, OSI, and S100B values were significantly higher in the patient group than in the control group ( $P<0.001, P<0.001$, and $P=0.007$, respectively). Conversely, the TAS levels of patients were significantly lower than those of controls $(P=0.014)$ (Table 2).

\section{Discussion}

The key finding of our study is that the TOS values of the patient group were significantly higher than those of the control group. Several similar studies in the literature have reported increased TOS values in association with many psychiatric disorders. The TOS values were found to be
Table I Sociodemographic characteristics of patients with CD and healthy controls

\begin{tabular}{llll}
\hline & $\begin{array}{l}\text { Patients with } \\
\text { CD, } \mathbf{n = 3 7}(\%)\end{array}$ & $\begin{array}{l}\text { Control group, } \\
\mathbf{n}=\mathbf{4 2}(\%)\end{array}$ & P-value \\
\hline $\begin{array}{l}\text { Age (mean } \pm \text { SD) } \\
\text { Sex }\end{array}$ & $32.49 \pm 12.59$ & $28.88 \pm 8.79$ & 0.140 \\
$\quad$ Male & $12(32.4)$ & $21(50)$ & 0.114 \\
$\quad$ Female & $25(67.6)$ & $21(50)$ & \\
Educational status & & & \\
$\quad \begin{array}{l}\text { Primary school } \\
\text { High school }\end{array}$ & $14(37.8)$ & $16(38.1)$ & 0.661 \\
$\quad$ University & $9(24.3)$ & $7(16.8)$ & \\
$\begin{array}{l}\text { Occupational status } \\
\text { Employed }\end{array}$ & $19(51.4)$ & $19(45.2)$ & 0.727 \\
$\quad \begin{array}{l}\text { Unemployed } \\
\text { Student }\end{array}$ & $14(37.8)$ & $16(45.2)$ & \\
\hline
\end{tabular}

Abbreviation: $\mathrm{CD}$, conversion disorder.

elevated in two studies of schizophrenia and schizoaffective disorder. ${ }^{18,19}$ Similarly, high TOS values were reported in studies of major depression, bipolar disorder, adult and pediatric ADHD, and childhood OCD. ${ }^{9,10,20-22}$ In contrast, low TOS values were reported in a study conducted in adult patients with OCD. ${ }^{23}$ Increased TOS levels in patients with CD indicate that oxidative stress is increased in these patients.

Our second most important finding is that the TAS values of the patient group were significantly lower than those of the control group. This is consistent with similar studies that reported lower TAS values in patients with generalized anxiety disorder, schizophrenia, major depression, bipolar disorder, childhood ADHD and hyperactivity disorder, and OCD than in the general population. ${ }^{8-10,19,24,25}$ Conversely, increased TAS values were reported in association with bipolar disorder, adult ADHD, and panic disorder. ${ }^{21,26,27} \mathrm{We}$ believe that the high TOS and low TAS values observed in our study are related to the inability of patients with CD to activate antioxidant systems sufficiently to deal with conditions of increased stress.

Another finding of our study is that the OSI was significantly higher in patients with $\mathrm{CD}$ than in the control group.

Table 2 Serum measures of subjects

\begin{tabular}{llll}
\hline & $\begin{array}{l}\text { Patients } \\
\text { with CD }\end{array}$ & $\begin{array}{l}\text { Control } \\
\text { group }\end{array}$ & P-value \\
\hline TAS (mmol Trolox equiv/L) & $1.16 \pm 0.32$ & $1.32 \pm 0.25$ & 0.014 \\
TOS ( $\mu$ mol $\mathrm{H}_{2} \mathrm{O}_{2}$ equiv/L) & $37.60 \pm 0.25$ & $28.39 \pm 8$ & $<0.00 \mathrm{I}$ \\
OSI (arbitrary units) & $3.45 \pm 1.34$ & $2.18 \pm 0.56$ & $<0.00 \mathrm{I}$ \\
SIOOB & $32.49 \pm 12.60$ & $28.9 \pm 8.8$ & 0.007 \\
\hline
\end{tabular}

Note: Data are presented as mean \pm standard deviation.

Abbreviations: $\mathrm{CD}$, conversion disorder; OSI, oxidative stress index; SI00B, SI00 calcium-binding protein B; TAS, total antioxidant status; TOS, total oxidant status. 
OSI is accepted as an indicator of oxidative stress and is expressed as the ratio of TOS to TAS. ${ }^{28}$ The OSI was also reported to be significantly elevated in similar studies of pediatric patients with OCD and ADHD, and adult patients with generalized anxiety disorder. ${ }^{8-10}$ An explanation for the high OSI may be that the antioxidant levels could not be elevated sufficiently to fully remove stressors from the organism.

Finally, the S100B protein levels were significantly higher in the patient group than in the control group. S100B protein is expressed by astrocytes, and although it plays a protective role against neuronal damage under normal conditions, it may exacerbate neuronal damage at higher concentrations. ${ }^{29}$ High levels of S100B inhibit central nervous system function and may be indicative of central nervous system damage or defects. ${ }^{30}$ In the literature, S100B is used as an important biochemical marker for brain damage in patients with psychiatric disorders. Elevated S100B levels in the cerebrospinal fluid were found in patients with schizophrenia, major depression, neurodegenerative diseases, and the acute phase of bipolar disorder. ${ }^{31-33}$ In vitro, it has been shown that $\mathrm{S} 100 \mathrm{~B}$ induces oxidative stress. Functional changes in cortical areas were observed in patients with CD. Both structural and functional changes in subcortical structures, such as the thalamus and the basal ganglia, were detected in these patients. Additionally, functional disorders of the striato-cortico-thalamic circuit, which controls voluntary motor movements and sensorimotor function, were observed in these patients..$^{34,35} \mathrm{We}$ believe that increased levels of S100B may be indicative of neuronal damage in patients with $\mathrm{CD}$.

\section{Conclusion}

The increased TOS and OSI levels and the decreased TAS levels found in this study show that oxidative stress is one of the factors that contributes to the emergence of $\mathrm{CD}$, and the antioxidant response to oxidative stress in patients with $\mathrm{CD}$ is inadequate. The elevated levels of S100B may be indicative of neuronal damage. Our study is the first in the literature to report these findings and should be supported by additional studies.

The limitations of our study include its small sample size and its cross-sectional design. The strength of our study is that this is the first study aiming to explain the biological causes of a disease with primarily psychological symptoms. Without longitudinal studies and large sample sizes, it will be challenging to interpret the effect of oxidative stress on patients with CD.

\section{Acknowledgment}

This study was funded by the Harran University Board of Scientific Research Projects (Funding number: 15118).

\section{Disclosure}

The authors report no conflicts of interest in this work.

\section{References}

1. Freud S, Breuer J. Fräulein Anna O. In: Studies on hysteria. 3rd ed. Harmondsworth, UK: Penguin; 1974:73-102.

2. Sar V, Akyüz G, Dogan O, Oztürk E. The prevalence of conversion symptoms in women from a general Turkish population. Psychosomatics. 2009;50(1):50-58.

3. Hsieh MK, Chang CN, Hsiao MC, Chen WJ, Chen LH. Conversion paralysis after surgery for lumbar disc herniation. Spine (Phila Pa 1976). 2010;35(8):E308-E310.

4. Chandrasekaran R, Goswami U, Sivakumar V. Chitralekha Hysterical neurosis-a follow-up study. Acta Psychiatr Scand. 1994;89(1):78-80.

5. Haddad JJ. Oxygen sensingand oxidant/redox - related pathways. Biochem Biophys Res Commun. 2004;316(4):969-977.

6. Lohr JB. Oxygen radicals and neuropsychiatric illness. Some speculations. Arch Gen Psychiatry. 1991;48(12):1097-1106.

7. Bal N, Acar ŞT, Yazıcı A, Yazıcı K, Tamer L. Altered levels of malondialdehyde and vitamin $\mathrm{E}$ in major depressive disorder and generalized anxiety disorder. Düşünen Adam The Journal of Psychiatry and Neurological Sciences. 2012;25(3):206-211.

8. Emhan A, Selek S, Bayazıt H, Fatih Karababa İ, Katı M, Aksoy N. Evaluation of oxidative and antioxidative parameters in generalized anxiety disorder. Psychiatry Res. 2015;230(3):806-810.

9. Kul M, Unal F, Kandemir H, Sarkarati B, Kilinc K, Kandemir SB. Evaluation of oxidative metabolism in child and adolescent patients with attention deficit hyperactivity disorder. Psychiatry Investig. 2015; 12(3):361-366.

10. Kandemir H, Abuhandan M, Aksoy N, Savik E, Kaya C. Oxidative imbalance in child and adolescent patients with obsessive compulsive disorder. J Psychiatr Res. 2013;47(11):1831-1834.

11. Abuhandan M, Kandemir H, Geter S, Karababa F. Evaluation of oxidative status in children and adolescent patients with primary enuresis nocturna. Dicle Med J. 2014;41(1):123-127.

12. Rothermundt M, Ponath G, Glaser T, Hetzel G, Arolt V. S100B serum levels and long term improvement of negative symptoms in patients with schizophrenia. Neuropsychopharmacology. 2004;29(5): 1004-1011.

13. Schroeter ML, Steiner J. Elevated serum levels of the glial marker protein S100B are not specific for schizophrenia or mood disorders. Mol Psychiatry. 2009;14(3):235-237.

14. Wiesmann M, Wandinger KP, Missler U, et al. Elevated plasma levels of S-100B protein in schizophrenic patients. Biol Psychiatry. 1999; 45(11):1508-1511.

15. Rothermundt M, Missler $\mathrm{U}$, Arolt $\mathrm{V}$, et al. Increased S100B blood levels in unmedicated and treated schizophrenic patients are correlated with negative symptomatology. Mol Psychiatry. 2001;6(4):445-449.

16. Erel O. A novel automated method to measure total antioxidant response against potent free radical reactions. Clin Biochem. 2004;37(2):112-119.

17. Erel O. A new automated colorimetric method for measuring total oxidant status. Clin Biochem. 2005;38(12):1103-1111.

18. Bošković M, Vovk T, Kores Plesničar B, Grabnar I. Oxidative stress in schizophrenia. Curr Neuropharmacol. 2011;9(2):301-312.

19. Bulbul F, Virit O, Alpak G, et al. Are oxidative stress markers useful to distinguish schizoaffective disorder from schizophrenia and bipolar disorder? Acta Neuropsychiatr. 2014;26(2):120-124.

20. Cumurcu BE, Ozyurt H, Etikan I, Demir S, Karlidag R. Total antioxidant capacity and total oxidantstatus in patients with majör depression: impact of antidepressant treatment. Psychiatry Clin Neurosci. 2009;63(5):639-645.

21. Selek S, Altindag A, Saracoglu G, Celik H, Aksoy N. Prolidase activity and its diagnostic performance in bipolar disorder. J Affect Disord. 2011;129(1-3):84-86.

22. Selek S, Bulut M, Ocak AR, Kalenderoğlu A, Savaş HA. Evaluation of total oxidative status in adult attention deficit hyperactivity disorder and its diagnostic implications. J Psychiatr Res. 2012;46(4):451-455. 
23. Selek S, Herken H, Bulut M, et al. Oxidative imbalance in obsessive compulsive disorder patients: a total evaluation of oxidant-antioxidant status. Prog Neuropsychopharmacol Biol Psychiatry. 2008;32(2): 487-491.

24. Akyol O, Herken $\mathrm{H}, \mathrm{Uz}$ E, et al. The indices of endogenous oxidative and antioxidative processes in plasma from schizophrenic patients. The possible role of oxidant/antioxidant imbalance. Prog Neuropsychopharmacol Biol Psychiatry. 2002;26(5):995-1005.

25. Gałecki P, Szemraj J, Bieńkiewicz M, Florkowski A, Gałecka E. Lipid peroxidation and antioxidant protection in patients during acute depressive episode sand in remission after fluoxetine treatment. Pharmacol Rep. 2009;61(3):436-447.

26. Selek S, Savas HA, Gergerlioglu HS, Bulbul F, Uz E, Yumru M. The course of nitric oxide and superoxide dismutase during treatment of bipolar depressive episode. J Affect Disord. 2008;107(1-3):89-94.

27. Ersoy MA, Selek S, Celik H, et al. Role of oxidative and antioxidative parameters in etiopathogenesis and prognosis of panic disorder. Int $J$ Neurosci. 2008;118(7):1025-1037.

28. Kosecik M, Erel O, Sevinc E, Selek S. Increased oxidative stress in children exposed to passive smoking. Int J Cardiol. 2005;100(1):61-64.

29. Ahlemeyer B, Beier H, Semkova I, Schaper C, Krieglstein J. S-100 beta protects cultured neurons against glutamate- and staurosporine-induced damage and is involved in the antiapoptotic action of the 5 HT(1A)receptor agonist, Bay x 3702. Brain Res. 2000;858(1):121-128.
30. Bertsch T, Casarin W, Kretschmar M, et al. Protein S-100B: a serum marker for ischemic and infectious injury of cerebral tissue. Clin Chem Lab Med. 2001;39(4):319-323.

31. Schroeter ML, Abdul-Khaliq H, Krebs M, Diefenbacher A, Blasig IE. Neuron-specific enolase is unaltered whereas S100B is elevated in serum of patients with schizophrenia - original research and metaanalysis. Psychiatry Res. 2009;167(1-2):66-72.

32. Yang K, Xie GR, Hu YQ, Mao FQ, Su LY. The effects of gender and numbers of depressive episodes on serum S100B levels in patients with majör depression. J Neural Transm (Vienna). 2008;115(12): 1687-1694.

33. Otto M, Stein H, Szudra A, et al. S-100 protein concentration in the cerebrospinal fluid of patients with Creutzfeldt-Jakob disease. J Neurol. 1997;244(9):566-570.

34. Atmaca M. Somatoform bozukluklarda nörogörüntüleme [Neuroimaging in somatoform disorders: a review]. Türk Psikiyatri Dergisi. 2012;23(4):274-280. Turkish.

35. Browning M, Fletcher P, Sharpe M. Can neuroimaging help us to understandand classify somatoform disorders? A systematic and critical review. Psychosom Med. 2011;73(2):173-184.
Neuropsychiatric Disease and Treatment

\section{Publish your work in this journal}

Neuropsychiatric Disease and Treatment is an international, peerreviewed journal of clinical therapeutics and pharmacology focusing on concise rapid reporting of clinical or pre-clinical studies on a range of neuropsychiatric and neurological disorders. This journal is indexed on PubMed Central, the 'PsycINFO' database and CAS,

\section{Dovepress}

and is the official journal of The International Neuropsychiatric Association (INA). The manuscript management system is completely online and includes a very quick and fair peer-review system, which is all easy to use. Visit http://www.dovepress.com/testimonials.php to read real quotes from published authors. 